OPEN ACCESS

Edited by:

Luis Cláudio Nascimento Da Silva,

University of Copenhagen, Denmark

Reviewed by:

Michael L. Vasil,

University of Colorado School of

Medicine, USA

Iruka N. Okeke,

Haverford College and University of

Ibadan, USA

*Correspondence:

Sheila Nathan,

Faculty of Science and Technology,

School of Biosciences and

Biotechnology, National University of

Malaysia, 43600 Bangi, Selangor,

Malaysia

sheila@ukm.edu.my

Specialty section:

This article was submitted to

Antimicrobials, Resistance and Chemotherapy, a section of the journal

Frontiers in Microbiology

Received: 18 February 2015

Accepted: 23 March 2015

Published: 10 April 2015

Citation:

Eng S-A and Nathan S (2015) Curcumin rescues Caenorhabditis

elegans from a Burkholderia pseudomallei infection.

Front. Microbiol. 6:290

doi: 10.3389/fmicb.2015.00290

\section{Curcumin rescues Caenorhabditis elegans from a Burkholderia pseudomallei infection}

\author{
Su-Anne Eng and Sheila Nathan* \\ Faculty of Science and Technology, School of Biosciences and Biotechnology, National University of Malaysia, Bangi, \\ Malaysia
}

The tropical pathogen Burkholderia pseudomallei requires long-term parenteral antimicrobial treatment to eradicate the pathogen from an infected patient. However, the development of antibiotic resistance is emerging as a threat to this form of treatment. To meet the need for alternative therapeutics, we proposed a screen of natural products for compounds that do not kill the pathogen, but in turn, abrogate bacterial virulence. We suggest that the use of molecules or compounds that are non-bactericidal (bacteriostatic) will reduce or abolish the development of resistance by the pathogen. In this study, we adopted the established Caenorhabditis elegans-B. pseudomallei infection model to screen a collection of natural products for any that are able to extend the survival of $B$. pseudomallei infected worms. Of the 42 natural products screened, only curcumin significantly improved worm survival following infection whilst not affecting bacterial growth. This suggested that curcumin promoted B. pseudomallei-infected worm survival independent of pathogen killing. To validate that the protective effect of curcumin was directed toward the pathogen, bacteria were treated with curcumin prior to infection. Worms fed with curcumin-treated bacteria survived with a significantly extended mean-time-to-death $(p<0.0001)$ compared to the untreated control. In in vitro assays, curcumin reduced the activity of known virulence factors (lipase and protease) and biofilm formation. To determine if other bacterial genes were also regulated in the presence of curcumin, a genome-wide transcriptome analysis was performed on curcumin-treated pathogen. A number of genes involved in iron acquisition and transport as well as genes encoding hypothetical proteins were induced in the presence of curcumin. Thus, we propose that curcumin may attenuate B. pseudomallei by modulating the expression of a number of bacterial proteins including lipase and protease as well as biofilm formation whilst concomitantly regulating iron transport and other proteins of unknown function.

Keywords: Burkholderia pseudomallei, Caenorhabditis elegans, curcumin, antibiotic resistance, bacterial attenuation

\section{Introduction}

Burkholderia pseudomallei is the causative agent of the tropical disease, melioidosis, which is endemic in Southeast Asia and northern Australia (Wiersinga et al., 2006). Melioidosis accounts for the high overall mortality in northeast Thailand and is reported to be the third leading cause of 
death from infectious diseases after human immunodeficiency virus (HIV)-AIDS and tuberculosis (Limmathurosatkul et al., 2010). Despite growing efforts to develop immunoprophylaxis treatment for melioidosis (Hara et al., 2009; Patel et al., 2011; Choh et al., 2013; Silva and Dow, 2013), currently there is no vaccine available for clinical use. Thus, treatment of melioidosis is still solely dependent on a lengthy course of antibiotics. Nevertheless, B. pseudomallei is becoming increasingly resistant to a diverse group of antimicrobials including third generation cephalosporins whilst quinolones and aminoglycosides have no reliable effect (Puthucheary and Sam, 2012). For example, two important antibiotic candidates in melioidosis treatment are ceftazidime and amoxicillin-clavulanic acid and cases of resistance have been reported in recent years (Wuthiekanun et al., 2011). Therefore, therapeutic options are limited and the difficulty in achieving sterilization is not fully understood. Hence, there is an urgent need for new alternative treatments for this disease.

To alleviate the worldwide problem of multidrug resistant (MDR) bacteria such as the carbapenem-resistant Enterobacteriacea (Kumarasamy et al., 2010; Zilberberg and Shorr, 2013), new strategies have been developed to reduce the impact of antibiotic resistance. As the search for new antibiotics is proving to be a major problem, an alternative strategy being pursued globally is the search for new anti-infectives. Unlike traditional antibiotics that are either bacteriostatic or bactericidal, anti-infectives are known to target bacterial virulence (Clatworthy et al., 2007; Papa et al., 2013; Sarabhai et al., 2013) or alternatively, improve host immunity (Hamill et al., 2008; Nijnik, 2013; Kong et al., 2014b). Inhibition of virulence should prevent the onset of infection, persistence and damage to the host without threatening bacterial survival, thus reducing selection pressure toward the development of antibiotic resistance (Clatworthy et al., 2007; Cegelski et al., 2008).

The versatile nematode, Caenorhabditis elegans, was selected as the host model for this study. C. elegans has been widely used as a tool to elucidate host-pathogen interactions (Tan et al., 1999; Garsin et al., 2001; Lee et al., 2011). Many of the bacterial virulence factors identified to be crucial in the killing of $C$. elegans were also required for pathogenesis in mammals hence promoting the importance of the worm as a tool in anti-virulence drug discovery (Moy et al., 2006; Adonizio et al., 2008). An important resource of molecules in the search for new drugs against human diseases is natural products (Newman and Cragg, 2012). The availability of these natural products and their derivatives has enabled the identification of potential candidate anti-infectives toward clinical pathogens using the C. elegans infection model platform (Moy et al., 2006; Kong et al., 2014a). In addition, the in vivo whole animal screen allows simultaneous assessment of drug pharmacokinetics and toxicity.

In this study, we utilized the established C. elegans - B. pseudomallei infection model (O'Quinn et al., 2001; Gan et al., 2002; Lee et al., 2013) as a screening tool to assess a collection of natural products as potential anti-infectives toward B. pseudomallei. This screen identified a natural compound, curcumin, as a positive hit based on its ability to prolong the lifespan of infected worms. Curcumin is a polyphenol extracted from Curcuma longa. It is commonly used in cuisine and folk medicine especially in South and Southeast Asian countries. Anecdotal evidence has proposed that curcumin exhibits a number of beneficial properties such as antioxidant, anti-inflammatory, antiviral, antibacterial, antifungal and anti-cancer activities (Aggarwal et al., 2007). Curcumin is known to be antibacterial toward various pathogens (Moghadamtousi et al., 2014) and this could be attributed to the iron chelating property of curcumin that impedes bacterial growth. However, in this study we observed continued survival and growth of $B$. pseudomallei in the presence of curcumin. Nevertheless, pretreatment of the bacteria with curcumin prior to nematode infection resulted in enhanced survival of infected worms proposing the selective action of curcumin on pathogen virulence. Further transcriptome analysis was undertaken to provide more insight into the possible mode adopted by curcumin in its role as a potential anti-infective agent against $B$. pseudomallei.

\section{Materials and Methods}

\section{Bacterial Isolates and Nematode Strains}

B. pseudomallei clinical isolates R15 (Lee et al., 2007), K96243 (Holden et al., 2004) and UM6 as well as Enterococcus faecalis V583 were grown in BHI broth, Pseudomonas aeruginosa strain PA14 in King's B broth, Staphylococcus aureus strain NCTC83254 and methicillin-resistant S. aureus (MRSA) strain ATCC33591 in Trypticase Soy (TS) media while Escherichia coli strain OP50 and Salmonella typhimurium SL1344 were cultured in Luria Bertani (LB) broth. All bacterial cultures were grown aerobically at $37^{\circ} \mathrm{C}$ overnight. The wild type C. elegans Bristol N2 (N2) and rrf3(pk1426); $g l p-4(b n 2)$ strains were obtained from the Tan Laboratory at Stanford University USA. The worms were maintained on nematode growth medium (NGM) agar plates seeded with a lawn of the standard laboratory food source, E. coli OP50. Agesynchronization of the worms was conducted by the hypochlorite treatment of gravid worms as described by Shapira and Tan (2008). N2 worms were made sterile through RNAi knockdown of the pos-1 gene (Tabara et al., 1999) by feeding the worms with E. coli expressing double stranded RNA (dsRNA) directed against pos-1. Both sterile N2 and rrf-3(pk1426);glp-4(bn2) worms were grown at $25^{\circ} \mathrm{C}$ until they reached the young adult stage before they were used for infection.

\section{Natural Products}

A total of 42 natural products extracted from various plants and marine extracts were used in this study. These products were either obtained commercially or supplied by the Institute for Pharmaceuticals and Neutraceuticals Malaysia (IPharm). Preparation and the origin of samples UE-01-1 to UE-20 are described in Kong et al. (2014a). Extracts UE-21 and UE-22 were purchased from Cosway Pte. Ltd while UE-23 and UE-24 were acquired from ONI Global Pte. Ltd. and Cambert Ptd. Ltd., respectively. Information on the 42 natural products is available in Supplementary Data 1. Stock solutions for all the natural products were prepared in dimethyl sulfoxide (DMSO), filtered with a $0.2 \mu \mathrm{m}$ membrane filter and stored at $-20^{\circ} \mathrm{C}$ until further use.

\section{Anti-Infective Screening}

Screening of natural products was performed based on the protocol by Moy et al. (2006) with some modifications. 
Firstly, the screening medium comprising of 90\% M9 buffer, $10 \mu \mathrm{g} / \mathrm{mL}$ cholesterol, $10 \%$ B. pseudomallei overnight culture and $200 \mu \mathrm{g} / \mathrm{mL}$ natural extract was prepared and aliquoted into individual wells $(750 \mu \mathrm{L})$ in a 24 -well plate. Each extract was tested in triplicate wells. Infection began when 10 pos- 1 treated N2 young adult worms were transferred into each well and the plate was incubated at $25^{\circ} \mathrm{C}$ without agitation. In control wells, B. pseudomallei was replaced with $E$. coli OP50 while the extract was replaced with $1 \%$ DMSO. Worm survival was scored manually throughout the assay. Worms were scored as dead when they did not respond to gentle probing with a platinum worm picker. An extract was considered a positive hit if it resulted in an average worm survival of $>50 \%$ in at least 2 out of 3 independent assays at a point when $50 \%$ of the untreated worms survived the infection.

\section{Determination of Antimicrobial Properties of Positive Hits \\ Disc Diffusion Test}

The disc diffusion assay was carried out according to the method outlined by the Clinical and Laboratory Standards Institute (CLSI) M2-A9 (CLSI, 2006). The inoculum was prepared by diluting a $B$. pseudomallei overnight culture to $\mathrm{OD}_{595}=0.5\left(10^{8}\right.$ $\mathrm{cfu} / \mathrm{mL}$ ). A total of $100 \mu \mathrm{L}$ of the inoculum was spread on Mueller Hinton agar using glass beads. Each positive hit $(20 \mathrm{mg} / \mathrm{mL})$ was impregnated into individual sterile filter paper discs (Whatman No. $1,5 \mathrm{~mm})$ and left to dry overnight. Tetracycline $(200 \mu \mathrm{g} / \mathrm{mL})$ was used as the positive control while DMSO was used as the negative control. Dried impregnated discs were placed on the $B$. pseudomallei lawn and incubated at $37^{\circ} \mathrm{C}$ for $20 \mathrm{~h}$. The formation of a clear zone of inhibition around the disc indicated the presence of antimicrobial activity for the extract.

\section{Broth Microdilution Antimicrobial Test}

The observed antimicrobial property of positive hits was confirmed through the broth microdilution minimum inhibitory concentration (MIC) test (Wiegand et al., 2008). Positive hits were diluted twofold from 500 to $0.24 \mu \mathrm{g} / \mathrm{mL}$ in a 96 -well plate and an inoculum of $10^{6} \mathrm{cfu} / \mathrm{mL} \mathrm{B}$. pseudomallei was added into each well. This test was conducted using the anti-infective screening medium ( $90 \% \mathrm{M} 9$ buffer $+10 \% \mathrm{BHI}$ broth) in order to mimic the assay conditions above. The plate was incubated at $37^{\circ} \mathrm{C}$ for $20 \mathrm{~h}$. The same concentrations of tetracycline and DMSO were included as the positive and negative controls, respectively. The MIC of a positive hit was defined as the lowest concentration where no visible bacterial growth was observed. The minimum bactericidal concentration (MBC) was determined by spreading the culture from each well onto agar plates. The lowest concentration with no bacterial growth on an agar plate was deemed the MBC value for the particular hit.

Determination of curcumin antimicrobial effects on $B$. pseudomallei was conducted in standard medium (BHI broth) similar to the broth microdilution method above. Concentrations of curcumin ranging from 0.6 to $1200 \mu \mathrm{M}$ were tested along with their vehicle DMSO and tetracycline as controls. After incubation, cultures from each concentration were serially diluted, spotted on agar, incubated and the bacterial colony forming units (CFU) were enumerated. However, for the effect of curcumin on $P$. aeruginosa, E. coli OP50, S. typhimurium, E. faecalis, S. aureus and MRSA, CFU was not counted. Instead, cultures were spotted directly onto agar plates and incubated. The bacterial growth in each spot was visually compared to their respective DMSO control. The bacteria were considered susceptible to curcumin if there was a decrease in the visible growth when compared to the vehicle DMSO.

\section{C. elegans Survival Assay}

The liquid based survival assay was performed in the same manner as the anti-infective screen but with minor modifications. The pos-1 treated $\mathrm{N} 2$ young adult worms were replaced with 30 sterile $r r f-3(p k 1426) ; g l p-4(b n 2)$ young adult worms. The $r r f$ 3 (pk1426); $g l p-4(b n 2)$ worms carry a $g l p-4$ temperature sensitive mutation which results in germline-deficient worms when grown at $25^{\circ} \mathrm{C}$ (Beanan and Strome, 1992). Therefore, $r r f-3(p k 1426) ; g l p-$ $4(b n 2)$ worms were maintained at $16^{\circ} \mathrm{C}$ to produce gravid worms and subjected to hypochlorite treatment to obtain eggs. The eggs were seeded on NGM agar and grown to sterile young adult worms at $25^{\circ} \mathrm{C}$ that were then used for the infection assay. Alive and dead worms were scored every $4 \mathrm{~h}$ post-infection. Each extract was assayed in triplicate wells corresponding to a total of 90 worms. In control wells, extract was replaced with DMSO whereas B. pseudomallei was replaced with E. coli OP50.

We used a modified survival assay to investigate the effect of curcumin on the pathogenicity of B. pseudomallei in C. elegans. Firstly, B. pseudomallei was cultured overnight in the presence of curcumin $(50 \mu \mathrm{M}, 100 \mu \mathrm{M}$ or $543 \mu \mathrm{M})$ at $37^{\circ} \mathrm{C}$. The curcumintreated cultures were then centrifuged at $4000 \mathrm{~g}$ for $10 \mathrm{~min}$ at $4^{\circ} \mathrm{C}$. The supernatant was removed and the bacterial cell pellet was resuspended with fresh BHIB broth. The washing step was repeated to minimize curcumin content. The cell suspension was then used in the preparation of assay medium, which comprised only of $90 \%$ M9 buffer, $10 \%$ curcumin-treated culture and $10 \mu \mathrm{g} / \mathrm{mL}$ cholesterol without any further addition of curcumin into the assay medium. Infection began when 30 sterile $r r f-3(p k 1426) ; g l p-4(b n 2)$ young adult worms were added into the wells. For the negative control, B. pseudomallei was treated with DMSO instead of curcumin.

\section{Colony Forming Unit (CFU) Assay}

In vivo bacterial counts were determined according to the method of Ooi et al. (2012). At each time point, 10 live worms infected with $50 \mu \mathrm{M}$ curcumin-treated bacteria were randomly picked and briefly anesthetized in $25 \mathrm{mM}$ Lev. The worms were washed twice in $200 \mu \mathrm{l}$ antibiotic cocktail comprising $25 \mathrm{mM}$ Lev and $500 \mu \mathrm{g} / \mathrm{ml}$ kanamycin followed by incubation for at least 45 min to completely kill bacterial cells associated with the worm cuticle. Next, the worms were washed three times with $200 \mu \mathrm{l}$ of $25 \mathrm{mM}$ Lev to eliminate the killed bacteria and residual antibiotic. During the last washing step, the Lev was removed, leaving about $5 \mu \mathrm{l}$ in the tube. Prior to adding $50 \mu 1$ 1\% Triton X (SigmaAldrich, X100), the worms were enumerated and then homogenized with a motorized pestle. Serial dilutions were performed on the worm lysates. Briefly, $10 \mu \mathrm{l}$ of the worm lysate was spotted on Ashdown agar supplemented with $100 \mu \mathrm{g} / \mathrm{ml} \mathrm{Cm}$ using the drop 
plate method with modifications. Colonies were counted after incubating the plates at $37^{\circ} \mathrm{C}$ for $48 \mathrm{~h}$. Average colony numbers obtained from visually separate colonies were used for statistical analysis. Bacterial CFU per worm was calculated using the formula: (average colony number $\times$ dilution factor $\times 55 \mu$ l worm lysate $) /(10 \mu \mathrm{l}$ worm lysates plated $\times$ number of worms $)$. Three independent replicates were performed for the experiment. The phrase " $55 \mu$ l worm lysate" $(50 \mu l 1 \%$ Triton $X+5 \mu l$ Lev containing the worms) refers to the total worm lysate of which $10 \mu \mathrm{l}$ was used for plating.

\section{The Effect of Curcumin and Ethylene Glycol Tetraacetic Acid (EGTA) on B. pseudomallei Replication}

An overnight B. pseudomallei culture was diluted 100 fold in fresh broth supplemented with curcumin $(50 \mu \mathrm{M}, 100 \mu \mathrm{M}$ or $543 \mu \mathrm{M})$ or EGTA $(5 \mathrm{mM}$ or $10 \mathrm{mM})$. The subculture was thereafter incubated shaking $(250 \mathrm{rpm})$ at $37^{\circ} \mathrm{C}$. At 2-hourly intervals, CFU counts were determined and a growth curve was plotted. The doubling time $(\mathrm{g})$, was calculated from the exponential phase of the growth curve using the formula: $g=\mathrm{t} \log 2 /\left(\log \mathrm{N}_{t}-\log \right.$ $\mathrm{N}_{0}$ ) where $N_{0}=$ number of CFU at a point during log phase, $N_{t}=$ number of CFU at a different time point during log phase and $t=$ time interval between $N_{0}$ and $N_{t}$. DMSO (0.1\%) was used as the control.

\section{The Effect of Curcumin on B. pseudomallei Virulence Factors Hemolysin Test}

To determine if curcumin affects B. pseudomallei hemolysin, curcumin-treated $(50 \mu \mathrm{M}, 100 \mu \mathrm{M}$ or $543 \mu \mathrm{M})$ B. pseudomallei overnight culture was streaked on $5 \%$ rabbit blood agar and incubated at $37^{\circ} \mathrm{C}$ for $24 \mathrm{~h}$. During the preparation of the agar, the same amount of curcumin was added while the agar was still in molten state. As a control, B. pseudomallei was cultured in the presence of DMSO $(0.1 \%, 0.2 \%$ or $1.0 \%)$ and streaked on DMSO supplemented blood agar. After $24 \mathrm{~h}$ incubation, the presence and type of hemolysis was recorded.

\section{Lipase Test}

The effect of curcumin on B. pseudomallei lipase was determined using Rhodamine B-olive oil agar (Kouker and Jaeger, 1987). B. pseudomallei was co-cultured with $50 \mu \mathrm{M}, 100 \mu \mathrm{M}$ or $543 \mu \mathrm{M}$ curcumin overnight and subsequently spotted on Rhodamine B-olive oil agar supplemented with the same concentration of curcumin and then incubated at $37^{\circ} \mathrm{C}$ for $48 \mathrm{~h}$. As a control, $B$. pseudomallei was cultured in the presence of DMSO $(0.1 \%, 0.2 \%$ or $1.0 \%)$ and streaked on DMSO supplemented Rhodamine Bolive oil agar. After $48 \mathrm{~h}$, the plates were observed under UV light $(350 \mathrm{~nm})$. Lipase activity was indicated by orange-red fluorescent colonies.

\section{Protease Test}

The effect of $50 \mu \mathrm{M}$ curcumin on B. pseudomallei protease was determined using 3\% skim milk agar (Oxoid, UK). The overnight curcumin-treated bacterial culture was spotted on skim milk agar supplemented with $50 \mu \mathrm{M}$ curcumin and incubated at $37^{\circ} \mathrm{C}$ for
$48 \mathrm{~h}$. As a control, B. pseudomallei was cultured with $0.1 \%$ DMSO and spotted on $0.1 \%$ DMSO supplemented skim milk agar. After $48 \mathrm{~h}$ incubation, the formation of a halo was observed.

\section{The Effect of Curcumin on B. pseudomallei Biofilm Production}

The biofilm assay was conducted according to the protocol of Koh et al. (2013). Firstly, the known high biofilm producer $B$. pseudomallei UM6 was cultured overnight with $50 \mu \mathrm{M}$ curcumin at $37^{\circ} \mathrm{C}$. The overnight culture was diluted using fresh broth (BHI broth $+50 \mu \mathrm{M}$ curcumin) to $\mathrm{OD}_{595}=1$ to obtain a standardized inoculum. For the negative control, $50 \mu \mathrm{M}$ curcumin was replaced with $0.1 \%$ DMSO. The standardized inoculums $(200 \mu \mathrm{L})$ were dispensed into 8 wells of a 96-well plate and incubated at $37^{\circ} \mathrm{C}$ for $48 \mathrm{~h}$. Uninoculated $\mathrm{BHI}$ broth was included as the blank control. Following incubation, the wells were washed with $1 \mathrm{X}$ phosphate buffered saline (PBS) to remove non-adherent bacteria. Thereafter, the wells were fixed with $200 \mu \mathrm{L} 99 \%$ (v/v) methanol for $15 \mathrm{~min}$ and air-dried at room temperature. The wells were then stained with $200 \mu \mathrm{L}$ filtered $2 \%$ crystal violet for $5 \mathrm{~min}$. The excess stain was washed with water and the wells were air-dried. The stain bound bacterial cells were solubilized with $200 \mu \mathrm{L}$ of $95 \%(\mathrm{v} / \mathrm{v})$ ethanol and the released stain was measured at $570 \mathrm{~nm}$ using a microplate reader (Sunrise, Tecan, Switzerland).

\section{Whole Transcriptome Analysis}

The transcriptome analysis was conducted using the B. pseudomallei array and protocol previously described by Chieng et al. (2012). In brief, B. pseudomallei was cultured for $10 \mathrm{~h}$ (log-phase) with $50 \mu \mathrm{M}$ curcumin or $0.1 \% \mathrm{DMSO}$ as control at $37^{\circ} \mathrm{C}$. Total RNA was extracted using Trizol, purified with Qiagen's RNeasy Mini Kit and on-column DNase I digestion was performed. The concentration, quality, and integrity of all RNA samples were analyzed using the Nanodrop ${ }^{\circledR}$ ND-1000 and Agilent 2100 Bioanalyser. Only RNA samples with a RIN value of $\geq 9$ were selected for the next step. The RNA samples were polyadenylated using the A-plus ${ }^{\mathrm{TM}}$ Poly (A) Polymerase Tailing Kit (Epicentre). cDNA synthesis, labeling, and hybridization were performed according to the Agilent one-color microarray protocol. The polyadenylated RNA samples were reverse transcribed to cRNA, amplified, and labeled using Agilent's Low Input Quick Amp Labelling Kit. Next, the labeled cRNA samples were purified with the RNeasy Mini Kit and subjected to Nanodrop ${ }^{\circledR}$ ND-1000 reading. Only purified samples with a yield $>1.65 \mu \mathrm{g}$ and specific activity of $>9.0$ pmol Cy3 per $\mu \mathrm{g}$ cRNA were used for hybridization. The purified labeled cRNA samples $(800 \mathrm{ng}$ ) were fragmented using the Agilent Fragmentation Buffer. This step was conducted at $60^{\circ} \mathrm{C}$ for $30 \mathrm{~min}$. After that, the fragmentation reaction was stopped by cooling the samples on ice for $1 \mathrm{~min}$ followed by the addition of Agilent $2 \times$ Hi-RPM Hybridization Buffer. The hybridization samples were centrifuged at $13000 \mathrm{~g}$ for $1 \mathrm{~min}$ at room temperature. A total of $40 \mu \mathrm{L}$ of each of the hybridized samples was loaded onto each array on the probe slide. The array was hybridized at $65^{\circ} \mathrm{C}$ for $17 \mathrm{~h}$. Washing steps were done with the Agilent GE Wash Buffer 
according to the manufacturer's protocol. The arrays were then scanned on the Agilent Technologies Scanner.

Spot intensities and quality control features of each array were extracted using the Agilent Feature Extraction Software. The processed signals were filtered and normalized with BRBArrayTools (http://linus.nci.nih.gov). The resultant data were subjected to TIGR-MeV software for Significance Analysis of Microarray (SAM) analysis in which a two class unpaired analysis was performed and genes with a false discovery rate $(\mathrm{FDR})<0.01$ and fold change $\geq 1.5$ were defined as significantly differentially expressed. Functional classifications were carried out based on Comprehensive Microbial Resources (CMR) annotations (www. cmr.jcvi.org). Gene function enrichment analysis was performed against the DAVID 6.7 database (http://david.abcc.ncifcrf.gov/ home.jsp) using the Fisher Exact test with Benjamini and Hochberg multiple testing correction $(p<0.05)$. The microarray result was validated using quantitative real-time PCR (qRT-PCR) analysis. qRT-PCR was conducted with the iScript One-Step RT-PCR kit with SYBR Green according to the manufacturer's instructions (Bio-Rad Laboratories) on the Bio-Rad iCycler. The gene BPSL2758 $(g l y A)$ that encodes for hydroxymethyltransferase was used as the reference as it did not show any significant changes in expression from the microarray experiment.

\section{Quantitative Estimation of Siderophore}

The ability of curcumin to induce $B$. pseudomallei siderophore production was confirmed by using the Chrome Azurol S-liquid assay (CAS) (Schwyn and Neilands, 1987). The CAS assay detects a change in color from the blue CAS-iron complex to orange free dye when the bound iron is competitively chelated by a higher iron affinity siderophore from the complex. B. pseudomallei was cultured under the same conditions as that for the transcriptome experiment ( $10 \mathrm{~h} \log$ phase) with either $50 \mu \mathrm{M}$ curcumin or vehicle $0.1 \% \mathrm{DMSO}$ at $37^{\circ} \mathrm{C}$. The cultures were then centrifuged at $4000 \mathrm{~g}$ for $10 \mathrm{~min}$ at $4^{\circ} \mathrm{C}$. The supernatants were filtered with a $0.2 \mu \mathrm{m}$ membrane filter to remove residual bacterial cells. The supernatants $(100 \mu \mathrm{L})$ were then transferred into 5 wells in a 96-well plate, representing 5 technical replicates. An equal amount of CAS assay solution (Schwyn and Neilands, 1987) containing $4 \mathrm{mM} 5$-sulfosalicylic acid was added into each well. The 5-sulfosalicylic acid acts as a CAS shuttle solution to increase the rate of iron exchange. Two reference blanks (BHI broth $+50 \mu \mathrm{M}$ curcumin and BHI broth $+0.1 \%$ DMSO) without the addition of bacteria culture were included in the assay. Upon addition of the CAS assay solution, the plate was measured at $630 \mathrm{~nm}$ after equilibrium was reached (approximately $1 \mathrm{~h}$ ). The relative percentage of siderophore produced by both untreated and curcumin-treated $B$. pseudomallei was then calculated and compared.

\section{Statistical Analysis}

Results from worm survival assays were analyzed using the Kaplan-Meier nonparametric survival analysis in Statview ${ }^{\circledR}$ 5.0.1 (SAS Institute, Inc). The data were presented as mean \pm standard deviation (SD) of a representative from at least two independent experiments. The data from the rest of the assays were expressed as mean \pm standard error of the mean (SE) from at least two independent assays. Statistical analyses were performed using the unpaired, two-tailed Student's $t$-test.

\section{Results}

\section{Identification of Potential Anti-Infectives Using the C. elegans - B. pseudomallei System}

Based on previous studies, B. pseudomallei is able to infect and kill C. elegans (O'Quinn et al., 2001; Gan et al., 2002; Lee et al., 2013). Using this system, several possible virulence determinants have been successfully elucidated (Gan et al., 2002; Puah et al., 2014). In this study, we extended the utility of the B. pseudomallei-C. elegans infection model to screen for anti-infectives that rescue the worm from infection. With this approach, we aimed to identify potential hits that attenuate the bacterial virulence factors. Throughout the study, the B. pseudomallei R15 clinical isolate was used unless stated otherwise. From the screen of 42 natural products, seven positive hits were obtained (Figure 1). These positive hits were UE-08, UE-09, UE11, UE-14, UE-15, UE-18, and UE-21. These positive hits were able to enhance the survival of infected worms exceeding $50 \%$ survival at a point where half of the untreated worms succumbed to infection. We also noted that treatment with a number of these natural products resulted in lower worm survival when compared to the untreated control. Testing of selected natural products on E. coli OP50 fed worms indicated that these compounds are toxic to the host. For example, UE-03-4 and UE-03-5 treated worms killed the worms even in the absence of infection when compared to the untreated control (data not shown).

The extended lifespan of infected worms in the presence of these positive hits could be attributed to the possible antimicrobial property of the natural products toward B. pseudomallei. However, we were only interested in potential extracts that were not antimicrobial in nature to reduce the possibility of the pathogen developing resistance to the selected hit(s). To delineate the selected positive hits into those with or without antimicrobial activity toward B. pseudomallei, we performed the disc diffusion and MIC tests. From the disc diffusion test, only one hit, UE-08, formed a zone of inhibition around the disc (Figure 2). The antimicrobial effect of all the positive hits was also determined through the broth microdilution MIC test. Again, only UE-08 exhibited an MIC value of $250 \mu \mathrm{g} / \mathrm{mL}$ and an MBC value of $500 \mu \mathrm{g} / \mathrm{mL}$. This proposed that UE- 08 enhanced the survival of infected worms by reducing the number of infecting bacteria. UE-08 is the crude extract of Curcuma longa. One of the wellestablished active ingredients of $C$. longa is curcumin and in this study, curcumin is represented by the positive hit UE-15. However, UE-15 did not show any anti-B. pseudomallei activity in both tests. The antimicrobial activity of the crude extract could be due to the existence of other components of $C$. longa such as diarylpentanoids, monoterpenes, sesquiterpenes, diterpenes, triterpenoids, alkaloid and sterols (Li et al., 2011). For example, terpenoids from $C$. longa were reported to possess antibacterial killing of various pathogens (Afzal et al., 2013). Thus, UE-08 was omitted from further analysis.

A more stringent survival assay was performed on the remaining positive hits utilizing a larger number of worms 


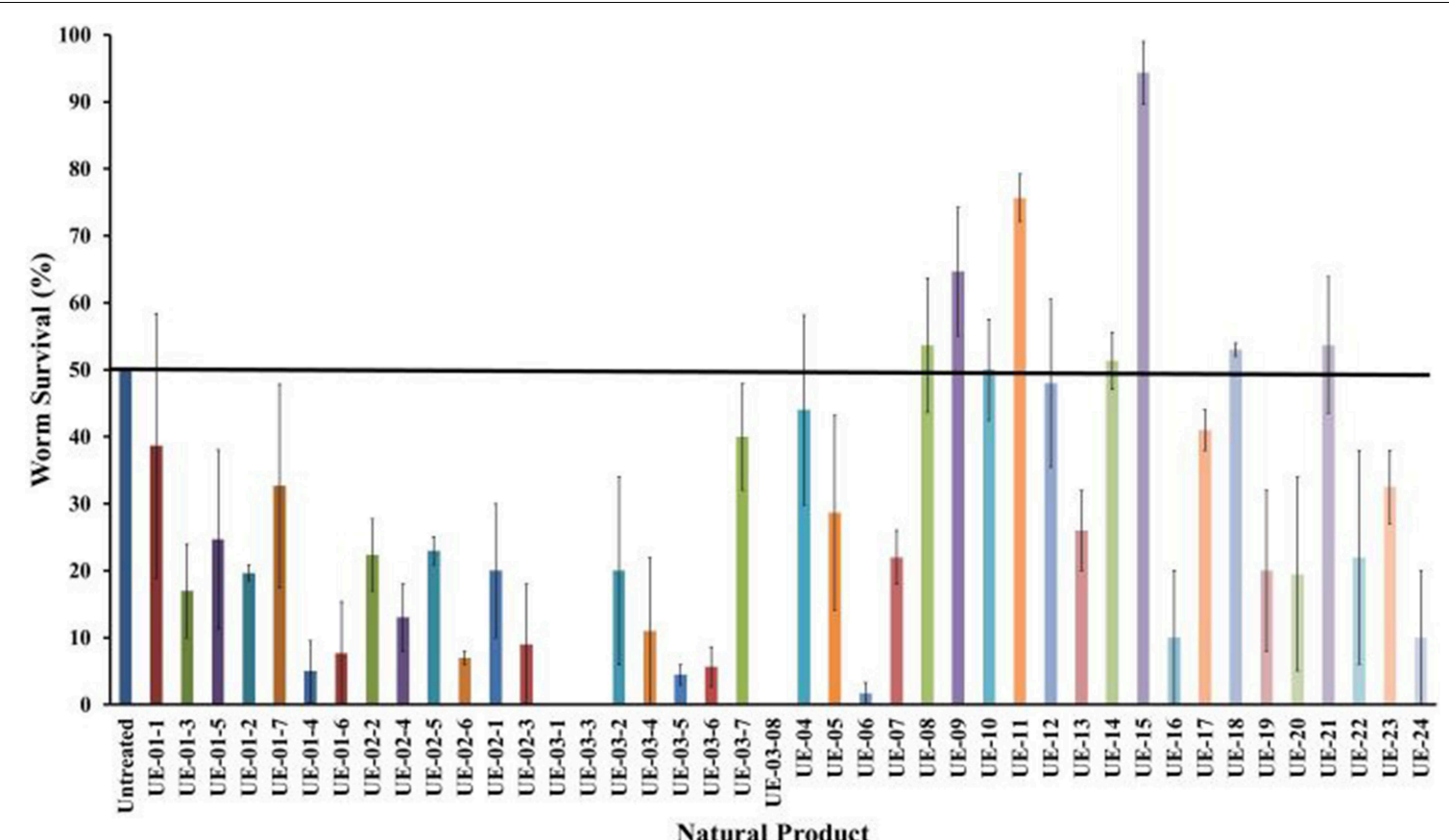

FIGURE 1 | Natural products enhanced the survival of B. pseudomallei infected worms. The chart above compares the hits from the screen performed on 42 natural products $(200 \mu \mathrm{g} / \mathrm{mL})$. The data are plotted at the point where $50 \%$ of the untreated worms survived the infection. Natural products resulting in survival exceeding the untreated control were selected for further analysis. Results are expressed as mean \pm SE from at least two independent assays.
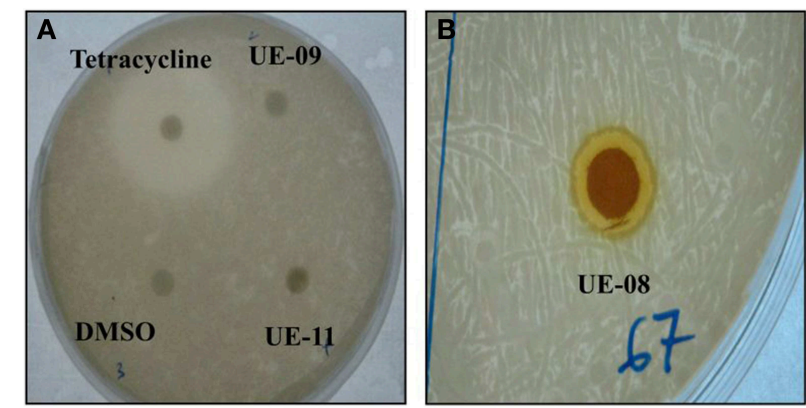

FIGURE 2 | Antimicrobial property of positive hits toward

B. pseudomallei. (A) A clear zone of $30 \mathrm{~mm}$ was formed for the positive control (tetracycline) while no zone of inhibition was observed for the negative control (DMSO). No inhibition zones were formed for UE-09 and UE-11 implying that they did not exert antimicrobial effect on the bacteria. (B) The formation of a clear inhibition zone $(9 \mathrm{~mm})$ around the disc indicated susceptibility of the bacteria to UE-08.

and additional time points to verify the anti-infective activities. Out of the positive hits tested, only UE-15 significantly prolonged the lifespan of B. pseudomallei infected worms $(p<$ 0.0001) when compared to the untreated control (Figure 3A). The mean-time-to death ( $\left.\mathrm{TD}_{\text {mean }}\right)$ of infected untreated worms was $21.019 \pm 0.975 \mathrm{~h}$ and this was extended to $24.938 \pm 0.522 \mathrm{~h}$ upon UE-15 treatment. As mentioned above, UE-15 is curcumin (Figure 3B), a polyphenol component of C. longa. Tables 1, 2 summarize the data obtained for the C. elegans survival assays and antimicrobial tests respectively.

\section{Curcumin Rescues Worms from B. pseudomallei Infection with a Mechanism Distinct from Conventional Antibiotics}

From the screen, we identified curcumin as a potential antiinfective agent as it is capable of extending worm survival without compromising bacteria viability. Nevertheless, we performed further analysis to validate the observed antimicrobial effects. Bacteria were cultured in the presence of different concentration of curcumin and viable bacterial counts were enumerated. Curcumin at concentrations between 0.6 and $600 \mu \mathrm{M}$ did not significantly reduce the number of CFU compared to the untreated bacteria (Figure 4A). At the higher concentration of $1200 \mu \mathrm{M}$, we are unable to make any conclusion as the concentration of DMSO (11.01\%) used is itself antimicrobicidal (Ansel et al., 1969). Nevertheless, the data allowed us to conclude that $543 \mu \mathrm{M}$ curcumin (the concentration used in the screens) was not antimicrobial toward B. pseudomallei. Tetracycline was used as the positive control and it significantly reduced $(p<0.01-p<0.0001)$ the number of CFU at concentrations from $2.3 \mu \mathrm{M}$ onwards (Figure 4A). The CFU data were used to plot growth curves for two strains of B. pseudomallei, K96243 and R15, grown in the presence of $50 \mu \mathrm{M}, 100 \mu \mathrm{M}$ or $543 \mu \mathrm{M}$ curcumin. No significant difference in growth rates was observed when compared to the untreated bacteria (Figure 4B). The doubling times calculated for B. pseudomallei strain R15 cultured in increasing 


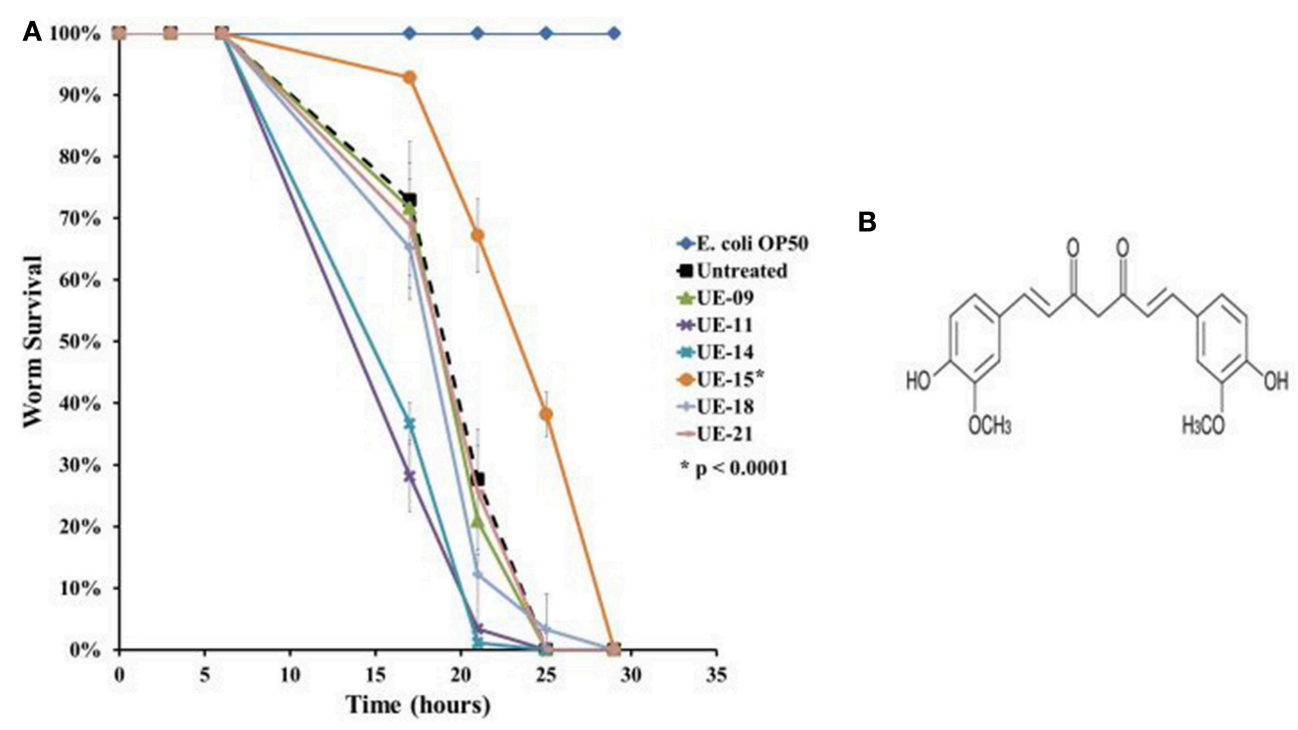

FIGURE 3 | UE-15 rescued C. elegans from B. pseudomallei infection. (A) The survival curves for worms treated with the 200 $\mu \mathrm{g} / \mathrm{ml}$ of the 6 positive hits. Treatment with UE-09, UE-11, UE-14, UE-18, and UE-21 failed to enhance the survival of infected worms whereas the addition of UE-15 extended the lifespan when compared to the untreated worms. Graph shows the mean $\pm S D$ from a representative of three independent assays. In a pair-wise analysis using the log-rank test, differences between UE-15 treated and untreated samples were significant $(p<0.0001)$. (B) Chemical structure of UE-15 or curcumin, a polyphenol from C. longa.
TABLE 1 | The list of positive hits and their effects on the survival of $B$. pseudomallei infected C. elegans.

\begin{tabular}{|c|c|c|c|c|}
\hline $\begin{array}{l}\text { Natural } \\
\text { product ID/ } \\
\text { Treatment }\end{array}$ & $\begin{array}{l}\text { Plant } \\
\text { species/ } \\
\text { compound }\end{array}$ & $\begin{array}{l}\text { Extraction } \\
\text { solvent }\end{array}$ & $\begin{array}{c}\text { Mean \% of } \\
\text { survival } \\
\text { (primary screen) }\end{array}$ & $\begin{array}{c}\text { Mean time to death } \\
\text { (hours } \pm \text { SD) } \\
\text { (secondary screen) }\end{array}$ \\
\hline $\begin{array}{l}\text { Untreated } \\
\text { (+DMSO) }\end{array}$ & & & 50.00 & $21.019 \pm 0.332$ \\
\hline UE-08 & C. longa & Water & 53.67 & na \\
\hline UE-09 & $\begin{array}{l}\text { Centella } \\
\text { asiatica }\end{array}$ & Water & 64.67 & $20.678 \pm 0.301$ \\
\hline UE-11 & $\begin{array}{l}\text { Eurycoma } \\
\text { longifolia }\end{array}$ & Water & 75.67 & $18.258 \pm 0.227$ \\
\hline UE-14 & $\begin{array}{l}\text { Emblica } \\
\text { officinalis }\end{array}$ & Water & 51.33 & $18.511 \pm 0.215$ \\
\hline UE-15 & Curcumin & & 94.33 & $24.938 \pm 0.522^{\star}$ \\
\hline UE-18 & $\begin{array}{l}\text { Silybum } \\
\text { eburneum }\end{array}$ & Water & 53.00 & $20.202 \pm 0.302$ \\
\hline UE-21 & Chorella & & 53.67 & $20.778 \pm 0.318$ \\
\hline
\end{tabular}

na-The survival of UE-08 treated worms was not available as this compound was not chosen for the secondary screen.

${ }^{*} p<0.0001$.

curcumin concentrations were $1.08 \pm 0.07 \mathrm{~h}(50 \mu \mathrm{M}), 1.15 \pm$ $0.18 \mathrm{~h}(100 \mu \mathrm{M})$, and $1.26 \pm 0.05 \mathrm{~h}(543 \mu \mathrm{M})$ compared to 1.09 $\pm 0.13 \mathrm{~h}$ for bacteria grown in the absence of curcumin. On the other hand, the doubling times for the reference strain K96243 were $1.20 \pm 0.11 \mathrm{~h}(50 \mu \mathrm{M}), 1.25 \pm 0.04 \mathrm{~h}(100 \mu \mathrm{M})$, and $1.23 \pm$ $0.06 \mathrm{~h}(543 \mu \mathrm{M})$ compared to $1.25 \pm 0.08 \mathrm{~h}$ in the untreated bacteria. This confirmed that curcumin did not affect the growth of B. pseudomallei.
TABLE 2 | The antimicrobial effect of positive hits against $B$. pseudomallei.

\begin{tabular}{llccc}
\hline $\begin{array}{l}\text { Natural } \\
\text { product ID/ } \\
\text { Treatment }\end{array}$ & $\begin{array}{l}\text { Plant } \\
\text { species/ } \\
\text { compound }\end{array}$ & $\begin{array}{c}\text { Diameter of } \\
\text { zone of } \\
\text { inhibition }(\mathbf{m m})\end{array}$ & $\begin{array}{c}\text { MIC } \\
(\mu \mathbf{g} / \mathbf{m L})\end{array}$ & $\begin{array}{c}\text { MBC } \\
(\mu \mathbf{g} / \mathbf{m L})\end{array}$ \\
\hline Untreated & & - & - & - \\
(+DMSO) & C. longa & 30 & 0.49 & $>500$ \\
Tetracycline & C. asiatica & 9 & 250 & 500 \\
UE-08 & E. longifolia & - & - & - \\
UE-09 & E. officinalis & - & - & - \\
UE-11 & Curcumin & - & - & - \\
UE-14 & S. eburneum & - & - & - \\
UE-15 & Chorella & - & - & - \\
UE-18 & UE-21 & - & - & - \\
\hline
\end{tabular}

DMSO and tetracycline were used as negative and positive controls respectively. - No visible reduction of growth was observed.

To determine if curcumin demonstrated antimicrobial activity toward other pathogens, the antimicrobial assay was repeated on three Gram-negative bacteria (E. coli OP50, P. aeruginosa, and S. typhimurium) and three Gram-positive bacteria (E. faecalis, S. aureus, and MRSA). The growth of E. coli OP50 (Figure 5A) and E. faecalis (Figure 5B) were visibly reduced at $1200 \mu \mathrm{M}$ curcumin. Furthermore, curcumin also affected the viability of both S. aureus (Figure 5C) and MRSA (Figure 5D) at $600 \mu \mathrm{M}$ and $1200 \mu \mathrm{M}$ curcumin. Our results are in concordance with the findings of Gunes et al. (2013) which reported the antibacterial effects of curcumin on E. coli, E. faecalis, S. aureus, and MRSA. Moreover, Kong et al. (2014a) also identified curcumin as a positive hit in a similar screen conducted on S. aureus in C.elegans 

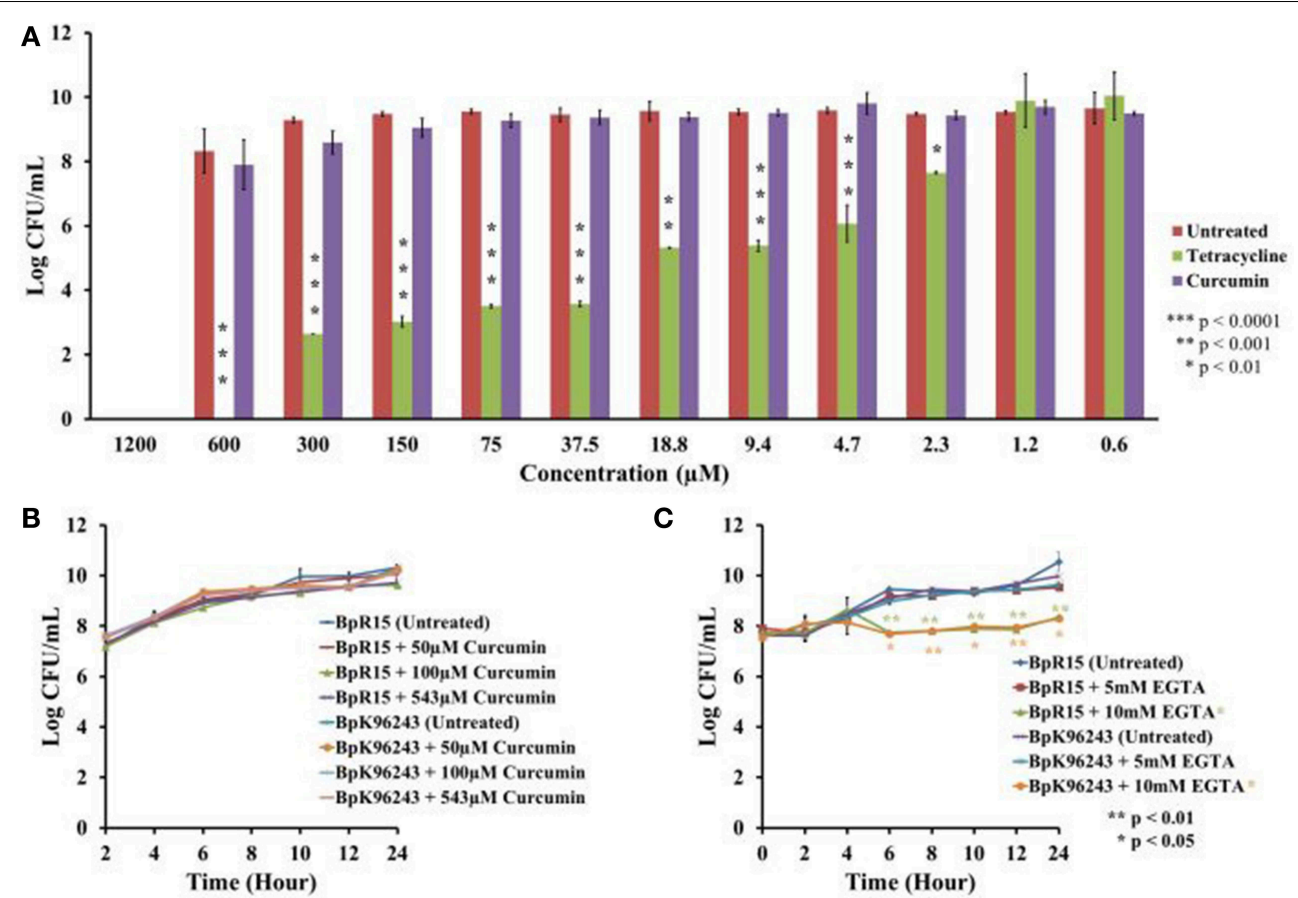

FIGURE 4 | Curcumin exhibited no antimicrobial effect on $B$. pseudomallei. (A) At concentrations ranging from $0.6 \mu \mathrm{M}$ to $600 \mu \mathrm{M}$, curcumin did not affect bacterial growth as reflected by the insignificant decrease in CFU when compared to the untreated control. DMSO at a concentration of $11.01 \%$ was antibacterial and prevented further analysis with curcumin at $1200 \mu \mathrm{M}$. The positive control, tetracycline, significantly decreased the number of CFU from 2.3 $\mu \mathrm{M}$ onwards. The bar chart corresponded to mean \pm SE from three independent assays. (B) Growing

B. pseudomallei in the presence of $50 \mu \mathrm{M}, 100 \mu \mathrm{M}$, and $543 \mu \mathrm{M}$ curcumin did not affect pathogen growth when compared to the untreated control. The graph shows the mean \pm SE from three independent assays. (C) Treatment of $B$. pseudomallei with EGTA affected bacterial growth in a dose dependent manner. At 5 mM EGTA, no significant reduction of growth was observed. However, treatment with $10 \mathrm{mM}$ EGTA significantly restricted the growth of B. pseudomallei when compared to the untreated control. The graph shows the mean \pm SE from two independent assays.
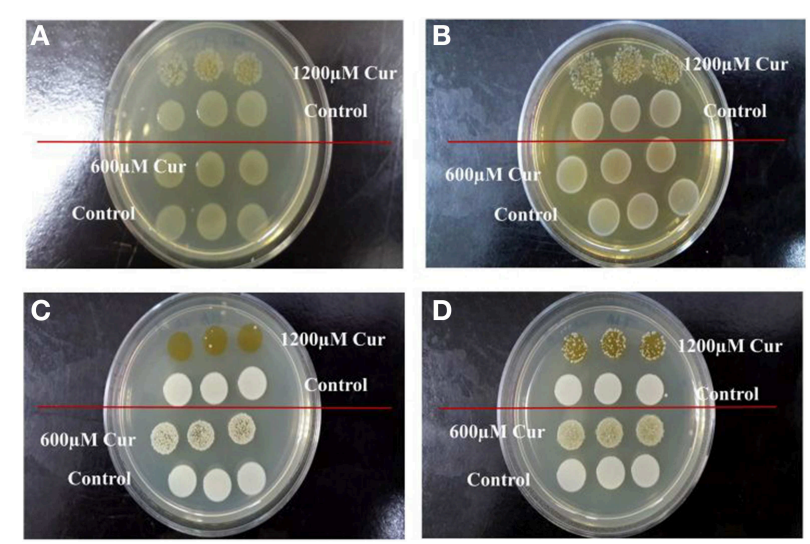

FIGURE 5 | Curcumin inhibited the growth of Gram negative and positive bacteria. Antimicrobial effect of curcumin on (A) E. coli OP50, (B) E. faecalis, (C) S. aureus, and (D) MRSA. At $1200 \mu \mathrm{M}$ curcumin, growth of (A) E. coli OP50 and (B) E. faecalis was reduced when compared to the untreated control. On the other hand, the growth of (C) S. aureus and (D) MRSA was inhibited by $600 \mu \mathrm{M}$ curcumin and more prominent at $1200 \mu \mathrm{M}$.

infection model. However, in that report, the enhanced worm lifespan was an outcome of a reduced number of infecting bacteria in the presence of curcumin. Although our study has demonstrated a negative effect of curcumin on $P$. aeruginosa, the antimicrobial outcome of curcumin has been widely reported (Gunes et al., 2013; Moghadamtousi et al., 2014). In addition, the inability of curcumin to affect $S$. typhimurium growth in vitro mirrors the finding that curcumin promotes $S$. typhimurium proliferation (Marathe et al., 2010). Hence, we propose that, whilst in general curcumin is able to inhibit bacterial growth, it does not hinder B. pseudomallei growth. Thus, curcumin rescues C. elegans from a $B$. pseudomallei infection using a mechanism distinct from conventional antibiotics.

As mentioned above, anti-infectives are able to either attenuate the pathogen or alternatively, strengthen host immunity. In both the screening and infection assays, curcumin was present in the growth medium. As such, we are unable to determine how the compound exerted its ability to rescue the infected worms. In this study, we were interested in pursuing anti-infectives that target bacterial virulence factors. To address this, the survival assay was modified whereby B. pseudomallei was pre-treated with $50 \mu \mathrm{M}, 100 \mu \mathrm{M}$ or $543 \mu \mathrm{M}$ curcumin overnight prior to nematode infection. Following the overnight incubation, the curcumin-treated bacteria were pelleted, washed and resuspended in fresh BHIB broth. Curcumin pre-treated bacteria resulted in significant extension of worm survival when compared to worms infected with untreated bacteria $(p<0.0001)$ (Figure 6). The $\mathrm{TD}_{\text {mean }}$ was highest when the 
bacteria were treated with $543 \mu \mathrm{M}$ curcumin: $43.910 \pm 1.663 \mathrm{~h}$ compared to $26.724 \pm 0.642 \mathrm{~h}$ for the untreated control. The $\mathrm{TD}_{\text {mean }}$ for both $50 \mu \mathrm{M}$ and $100 \mu \mathrm{M}$ were comparable at 34.839 $\pm 1.426 \mathrm{~h}$ and $33.194 \pm 1.358 \mathrm{~h}$, respectively. This suggested that curcumin is able to attenuate $B$. pseudomallei most likely by targeting its virulence factor(s). In addition, worms infected with

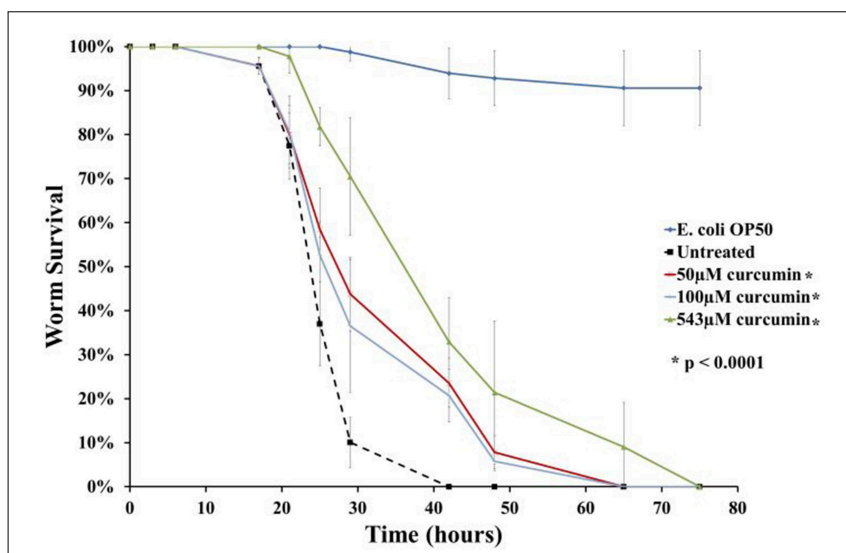

FIGURE 6 | Curcumin targets B. pseudomallei to rescue C. elegans from infection. The chart above demonstrates worm survival following pre-treatment of B. pseudomallei with curcumin where the lifespan of worms was extended compared to the untreated control. The graph shows the mean \pm SD from at least two independent assays. In a pair-wise analysis using the log-rank test, differences between treatment and control were significant.
$50 \mu \mathrm{M}$ curcumin-treated bacteria were homogenized and bacterial counts were enumerated. Up to $12 \mathrm{~h}$ post infection, no significant difference was observed in bacterial intestinal colonization when compared to worms fed with untreated bacteria. The bacterial counts for worms infected with curcumin pre-treated bacteria at 4,8 , and $12 \mathrm{~h}$ post-infection were $1.58 \pm 0.37,1.26 \pm 0.10$, and $2.05 \pm 0.26 \log \mathrm{CFU} /$ worm respectively whereas the bacterial counts for the untreated controls were $1.18 \pm 0.03,1.19 \pm$ 0.01 , and $1.97 \pm 0.19 \log \mathrm{CFU} /$ worm respectively.

\section{Curcumin Attenuates Lipase, Protease and Biofilm Formation}

B. pseudomallei is known to secrete a number of virulence factors such as protease, lipase, hemolysin (Cheng and Currie, 2005) and the recently identified BLF-1 toxin (Cruz-Migoni et al., 2011). To evaluate the role of curcumin on selected secreted factors, we conducted in vitro biochemical tests on $B$. pseudomallei hemolysin, lipase and protease. The activity of these selected factors was monitored on blood agar, Rhodamine B-olive oil agar and skim milk agar, respectively. The respective agar plates were supplemented with curcumin to enable continuous exposure of the bacteria to curcumin throughout the assay period.

B. pseudomallei expresses the $\alpha$ and $\beta$ classes of hemolysin. $\alpha$-hemolysin is more commonly found among isolates and displays weak cytolytic activity that is observable only around heavy bacterial growth. On the other hand, $\beta$-hemolysin is produced infrequently but results in a clear hemolytic zone around single colonies (Ashdown and Koehler, 1990). B. pseudomallei R15 produced the more common $\alpha$-hemolysin which partially lysed
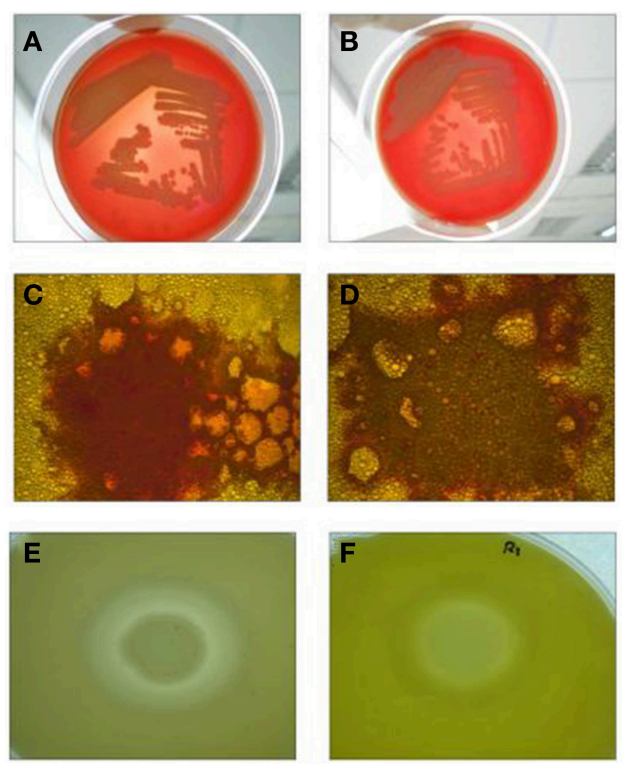

G

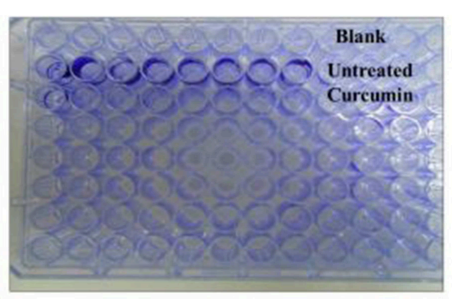

H

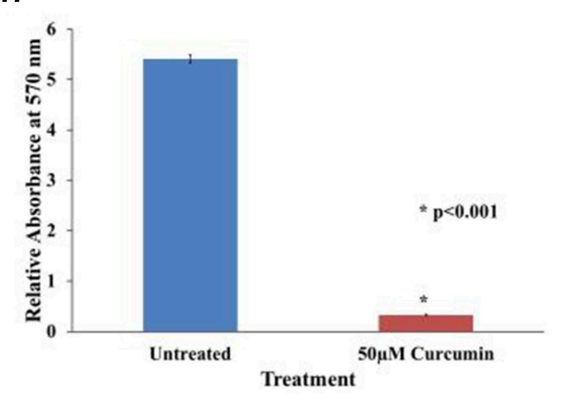

untreated control (C) when compare to the curcumin-treated cells (D). In the protease test, the formation of a large halo was observed in untreated cells (E) whilst a much smaller halo was observed in curcumin-treated bacteria (F). Biofilm formation was also reduced following curcumin treatment $\mathbf{( G , H )}$. The bar chart represents mean \pm $\mathrm{SD}$ from two independent assays. 
red blood cells (Figure 7A). This hallmark of $\alpha$-hemolysis is indicated by the presence of green colored biliverdin, a by-product of hemoglobin breakdown. Treatment with curcumin did not affect the activity of hemolysin as $\alpha$-hemolysis still occurred (Figure 7B).

In the lipase assay, we spotted untreated and curcumintreated B. pseudomallei on Rhodamine B-olive oil agar (Kouker and Jaeger, 1987). Hydrolysis of olive oil by lipase produces free fatty acids. Interaction of free fatty acids with Rhodamine $B$ produces orange-red fluorescence when viewed under UV light. Figures 7C,D depict our observations for both curcuminuntreated and curcumin-treated bacteria. Upon curcumin treatment, the intensity of the orange-red fluorescence was lower (Figure 7D) than the untreated control (Figure 7C). We also observed that this loss of intensity is more pronounced at higher concentrations of curcumin indicating that the effect of curcumin on lipase is dose dependent.

Curcumin also affected the activity or expression of B. pseudomallei protease. The principle of the skim milk agar assay is that protease will digest the opaque casein in the agar into transparent smaller peptides and amino acid resulting in the formation of a halo. The untreated B. pseudomallei culture hydrolysed the milk casein resulting in a clearly noticeable halo (Figure 7E). However, when the bacteria was grown in the presence of curcumin, the formed halo was smaller in size (Figure 7F). The ability of curcumin to inhibit protease activity has also been reported for curcumin-treated P. aeruginosa PA01 (Rudrappa and Bais, 2008).

Curcumin is also known to interfere with biofilm formation (Neelakantan et al., 2013; Packiavathy et al., 2014). Hence, we extended our investigation to determine if this was true for $B$. pseudomallei as well. As the R15 isolate is a poor biofilm producer, we used the B. pseudomallei UM6, a high biofilm producing strain (Chin et al., under review). In the presence of $50 \mu \mathrm{M}$ curcumin, biofilm formation was significantly reduced $(p<0.001)$ when compared to the untreated control (Figures 7G,H).

\section{Transcriptome Analysis Revealed Induction of Genes Involved in Iron Acquisition and Transport as Well as Hypothetical Proteins}

The ability of curcumin to inhibit $B$. pseudomallei lipase and protease as well as biofilm formation hinted at the possibility that more virulence determinants could be targeted by curcumin. We therefore measured the global transcriptome expression levels of curcumin-treated B. pseudomallei and compared them to the expression of untreated bacteria. We treated with bacteria with $50 \mu \mathrm{M}$ curcumin as this concentration was sufficient to rescue the infected worms (Figure 6) and also suppressed lipase and protease activity in addition to biofilm formation.

From the transcriptome analysis, we noted that curcumin significantly regulated the expression of 88 genes with 76 genes up-regulated and 12 genes down-regulated (Supplementary Data 2). Functional classification of these genes (Figure 8) showed that most of the induced genes were proteins of unknown function, hypothetical proteins and transport and binding proteins. Gene function enrichment analysis on the induced genes based on the KEGG biochemical pathways showed significant enrichment $\left(p=2.04 \times 10^{-5}\right)$ of ATP binding cassette (ABC) transporters specifically involving iron transport. On the other hand, no significant enrichment function was generated for the 12 repressed genes. Thus, all further discussion is limited to only the up-regulated genes.

Curcumin is a known iron chelator (Jiao et al., 2006), hence, it was not surprising to note the induction of genes involved in iron acquisition and transport (discussed below). A number of studies have proposed that the therapeutic effects of curcumin

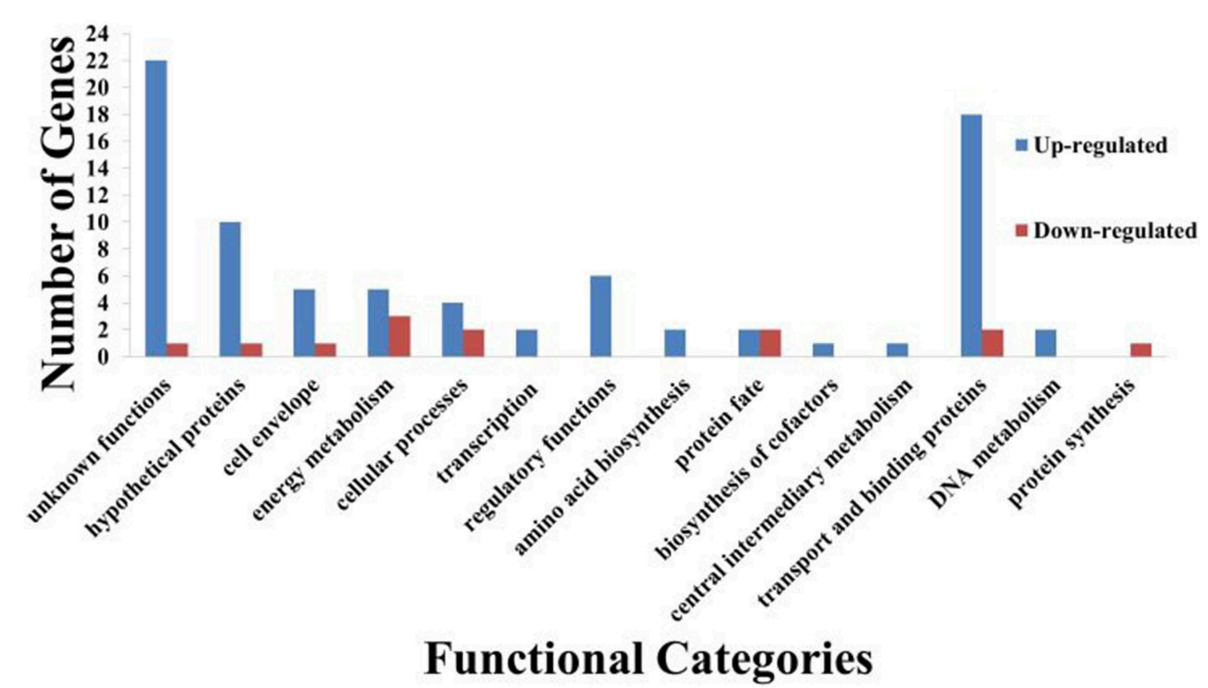

FIGURE 8 | Functional classification of curcumin regulated $B$. pseudomallei genes. A total of 88 genes were differentially regulated by curcumin with 76 genes up-regulated whilst 12 down-regulated. Bars indicate number of genes in each group that were significantly regulated by curcumin. Genes were divided into functional categories based on Comprehensive Microbial Resources (CMR) annotations. 
TABLE 3 | Curcumin-induced ABC-related iron acquisition genes.

\begin{tabular}{|c|c|c|c|}
\hline ABC System & Allocrite & Gene & Gene Description \\
\hline 1 & Malleobactin & BPSL1779 & Putative siderophore biosynthesis related $A B C$ transport protein \\
\hline 2 & Pyochelin & BPSS0590 & Probable ATP-binding component of ABC transporter \\
\hline \multirow[t]{3}{*}{3} & Ferric citrate or Ornibactin & BPSL1781 & Extracytoplasmic-function sigma-70 factor PvdS \\
\hline & Ferric citrate or Ornibactin & BPSL1783 & Putative iron transport-related exported protein \\
\hline & Ferric citrate or Ornibactin & BPSL1784 & Putative iron transport-related ATP-binding protein \\
\hline \multirow[t]{3}{*}{4} & Heme & BPSS0240 & Hemin ABC transport system, ATP-binding protein \\
\hline & Heme & BPSS0241 & Hemin ABC transport system, membrane protein \\
\hline & Heme & BPSS0244 & Exported heme receptor protein \\
\hline \multirow[t]{4}{*}{5} & Siderophore & BPSS1029 & tonB-family receptor \\
\hline & Siderophore & BPSS1204 & Iron transport receptor protein \\
\hline & Iron (III) & BPSL1277 & Putative $\mathrm{ABC}$ transport system, membrane protein (possibly iron-related) \\
\hline & Iron (III) & BPSL1278 & Putative ABC transport system, iron-binding exported protein \\
\hline
\end{tabular}

A

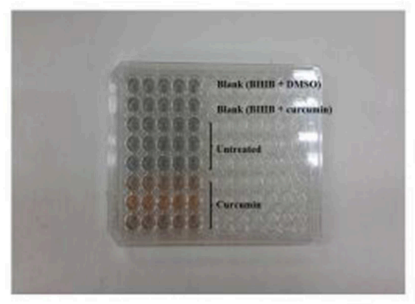

FIGURE 9 | The effect of curcumin on B. pseudomallei siderophore. (A) The CAS solution changes color from blue to orange upon curcumin treatment whereas the mixture for untreated control remained blue. (B) The
B

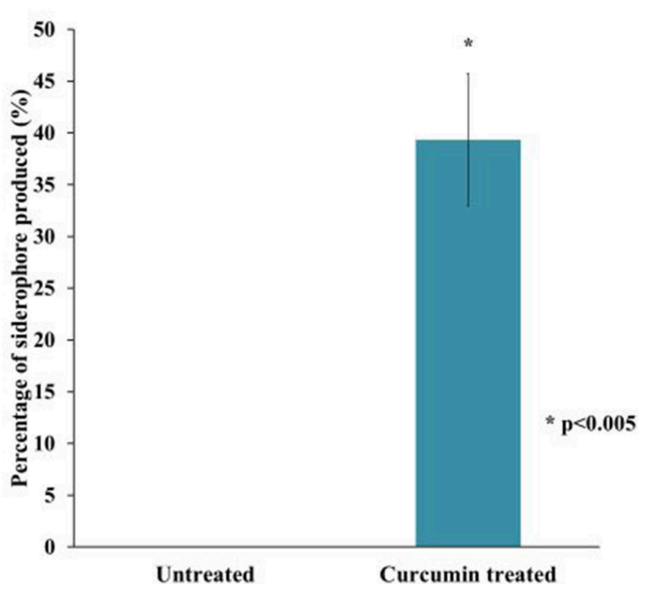

amount of siderophore detected was significantly higher in curcumin-treated bacteria than in the untreated control. The bar chart represents mean $\pm \mathrm{SE}$ from two independent assays. can be attributed to its iron chelating properties (Baum and $\mathrm{Ng}$, 2004; Jiao et al., 2009). In our study, the addition of curcumin led to reduced iron concentration in the growth media as a result of the chelation. Our findings are similar to data presented by Tuanyok et al. (2005) and Alice et al. (2006) whereby iron transport related genes were up-regulated in iron-deficient growth conditions. Iron is essential for the growth and development of all pathogens. Under iron-restricted conditions, bacteria overexpressed genes responsible for iron uptake in order to maintain viability (Tuanyok et al., 2005).

In Gram negative bacteria, transport of iron from the environment into the cell is an active process that requires the TonB system (Krewulak and Vogel, 2008). In brief, Gram negative bacteria secrete siderophores, molecules with high affinity for iron, to scavenge iron from the environment. The TonB system drives a proton motive force from the cytoplasmic membrane to TonB dependent transporters (TBDTs) located at the outer membrane. The energized TBDTs then actively transfer iron bound siderophores into the cell (Krewulak and Vogel, 2008). The TonB system is made up of three components: TonB, ExbB, and ExbD. In B. pseudomallei, these proteins are encoded by BPSS0368, BPSS0367, and BPSS0366 respectively. From our analysis, all three genes were up-regulated following curcumin treatment.

As mentioned earlier, functional enrichment analysis revealed that the majority of the induced genes are $\mathrm{ABC}$ transporters. We mapped our list of up-regulated genes to the previously annotated B. pseudomallei ABC systems (Harland et al., 2007) and noted that five of the $\mathrm{ABC}$ systems involved in iron acquisition were induced. The identity of the induced genes (12) corresponding to each system is presented in Table 3.

In addition to the TonB and $\mathrm{ABC}$ systems, we also observed an enrichment of siderophore-related genes. This suggests an increase in the biosynthesis of hydroxamate-type siderophores such as malleobactin and ornibactin as well as a mixed catecholate-hydroxamate pyoverdine corresponding to the over 
expressed BPSL1774-BPSL1787 cluster of genes. Within the BPSS0581-BPSS0594 cluster involved in pyochelin synthesis, a number of genes were also up-regulated, again, proposing the bacterial response to the low-iron environment in the presence of curcumin. We determined the amount of siderophore present in the growth media after curcumin treatment with the quantitative CAS-liquid assay. The amount of siderophore detected was significantly higher $(p<0.005)$ than the untreated control (Figure 9).

As iron is crucial for the optimal function of oxygen transport in living organisms, deprivation of iron will restrict cell growth and replication (Tuanyok et al., 2005). However, we had earlier noted that curcumin did not suppress the in vitro growth of $B$. pseudomallei (Figures 4A,B). On the other hand, in the presence of $5 \mathrm{mM}$ EGTA, another known iron chelator, no apparent difference in growth rates was observed between the EGTA treated and untreated B. pseudomallei (Figure 4C). However, when the bacteria were treated with $10 \mathrm{mM}$ EGTA, growth of both strains, K96243 and R15, was significantly reduced $(p<0.01-p<$ 0.05 ) from $6 \mathrm{~h}$ onwards when compared to the untreated control (Figure 4C). This is as expected as noted above, iron is essential for bacterial growth. For example, the addition of 2,2' dipyridyl (DIP), an iron chelator, inhibited the growth of bacteria in a dose dependent manner (Eijkelkamp et al., 2011). This proposed that unlike common iron chelators, curcumin acts in a manner that is independent of a reduction in cell viability. From the expression profile, we also observed that a number of genes involved in energy production are overexpressed in the presence of curcumin (Figure 8) proposing normal bacterial metabolism. The products of five genes (BPSL1554, BPSL1782, BPSL2469, BPSS0495, BPSS1855) that were induced may compensate for the loss of energy production caused by the three repressed genes (BPSL0247, BPSS0278, BPSS1744). Furthermore, the BPSS0495 gene that encodes a nitroreductase family protein was induced. The induction of this gene suggested that $B$. pseudomallei may use alternative sources such as nitrogen to generate energy. This idea is supported by the up-regulation of BPSS0369 that encodes bacterioferritin ferredoxin. The BPSS0369 gene is located upstream of the bacterioferritin gene ( $b f r$ ) encoding a 64 amino acid-residue protein identical to a region of NifU, a [2Fe2S] protein found in nitrogen-fixing bacteria (Tuanyok et al., 2005).

\section{Discussion}

Melioidosis has long been associated with high morbidity and mortality in endemic areas and requires protracted long-term antibiotic treatment (Wiersinga et al., 2006). Emergence of antibiotic resistant isolates (Wuthiekanun et al., 2011) demands for an urgent need for new alternative treatments. Therefore, the aim of our study was to search for anti-infectives that specifically target bacterial virulence thus reducing selection pressure toward resistance. Many studies have adopted a similar approach to disrupt pathways related to virulence including inhibiting toxin function, toxin delivery, regulation of virulence expression, bacterial adhesion and biofilm formation (Clatworthy et al., 2007; de la Fuente-Nunez et al., 2013). In general, the B. pseudomallei genome content is distributed over 2 chromosomes (chromosomes 1 and 2) that demonstrate significant functional partitioning. Chromosome 1 is associated with core functions such as cell metabolism and growth while chromosome 2 carries more genes required for accessory functions such as adaptation for survival and virulence factors (Holden et al., 2004). Our transcriptome data demonstrated that $62.5 \%$ ( 55 genes) of the differentially regulated genes are located in chromosome 2 whilst $37.5 \%$ ( 33 genes) are in chromosome 1 . The data from this study suggests that the anti-infective effect of curcumin targets more accessory functions compared to functions related to cell proliferation.

In our study, we used the B. pseudomallei-C. elegans infection model to screen a collection of natural products for any that rescued the worms from infection by means of attenuating bacterial virulence. One of these products, curcumin, was able to enhance worm survival without affecting bacterial survival. The approach we adopted involved screening all the natural products or constituent ingredients against the infected worms first, rather than beginning the study with the antimicrobial screen, in an effort to maximize our search for potential anti-infectives. Although some products are deleterious to the bacteria, at sub-MIC concentrations, they may be good anti-infective candidates capable of attenuating virulence factors (Rudrappa and Bais, 2008). Furthermore, the animal model screen would simultaneously allow us to identify products that rescue the worm via modulating the host immune response (Hamill et al., 2008; Easton et al., 2009). When we pre-treated both host and B. pseudomallei with curcumin prior to infection, we found that worm survival was enhanced under experimental conditions proposing that curcumin affects both host immunity (data not shown) and bacterial virulence and/or survival (Figure 6).

Curcumin, also known as diferuloylmethane, is a polyphenol derived from turmeric. Many beneficial characteristics of curcumin such as antimicrobial, anticancer, and antioxidant have been documented (Aggarwal et al., 2007). In recent years, curcumin has also attracted interest for its ability to delay aging and age-related diseases (Sikora et al., 2010; Liao et al., 2011). In our study, different biochemical tests demonstrated that curcumin affects $B$. pseudomallei lipase and protease. We also showed that curcumin impedes biofilm formation. Studies have shown that curcumin is anti-virulent toward various pathogens, mainly attributable to its anti-quorum sensing (anti-QS) trait (Rudrappa and Bais, 2008; Packiavathy et al., 2014). Bacterial QS systems regulate virulence especially the secretion of toxins and also biofilm formation (Antunes et al., 2010). We hypothesized that curcumin attenuates $B$. pseudomallei by inhibiting the QS mechanism. We went on to test this hypothesis by measuring the global gene expression in curcumin-treated bacteria.

Unexpectedly, the transcriptome analysis did not reflect the reduction in $B$. pseudomallei secretion of lipase and protease or biofilm formation. Expression of genes corresponding to these virulence factors and those involved in QS were not regulated. This may be a result of analysis on the bacteria at different phases of growth in the various experiments. Whilst the bacteria used in the C. elegans survival assays and biochemical tests were treated for $24-48 \mathrm{~h}$, a $10-\mathrm{h} \log$ phase curcumin-treated culture was used to harvest the RNA for transcriptome analysis. 
B. pseudomallei is known to express different sets of genes during distinct growth phases (Rodrigues et al., 2006). In our analysis, we found that most of the up-regulated genes encode proteins involved in iron acquisition and transport as well as hypothetical proteins and proteins of unknown function. The iron chelating effect of curcumin most likely created iron-restricted growth conditions which forced the bacteria to increase expression of iron acquisition and transport genes. Nevertheless, a large number of genes induced in the presence of curcumin are annotated as hypothetical and unknown function. Hence, it is possible that these genes could be coding for virulence related factors that contribute to the biofilm phenotype. The up-regulation of several transcriptional regulators also points to potential indirect effects which may directly or indirectly control these hypothetical proteins.

Siderophore has been proposed as a virulence factor of $B$. pseudomallei (Yang et al., 1993). Nevertheless, the induction of siderophore gene expression upon curcumin treatment did not lead to accelerated worm killing. On the other hand, survival of C. elegans fed with curcumin-treated bacteria was significantly enhanced when compared to the untreated control (Figure 6). As curcumin chelates iron, this may have affected bacterial fitness, hence, the bacteria switched their focus onto iron acquisition to ensure growth and maintenance rather than infection of the worms. The microarray analysis also showed more genes involved in energy metabolism were induced (Figure 8), supporting our observation that curcumin did not inhibit bacterial growth. Expression of BPSS0495 (nitroreductase family protein) and BPSS0369 (bacterioferritin ferredoxin) suggested that the bacteria were capable of utilizing alternative metabolic pathways for energy production.

In conclusion, we propose that curcumin is a potential antiinfective agent against $B$. pseudomallei. This natural product exerts non-favorable conditions on the bacteria's growth, thus,

\section{References}

Adonizio, A., Leal, S. M. Jr., Ausubel, F. M., and Mathee, K. (2008). Attenuation of Pseudomonas aeruginosa virulence by medicinal plants in a Caenorhabditi elegans model system. J. Med. Microbiol. 57, 809-813. doi: 10.1099/jmm.0. 47802-0

Afzal, A., Oriqat, G., Khan, M. A., Jose, J., and Afzal, M. (2013). Chemistry and biochemistry of terpenoids from Curcuma and related species. J. Biol. Active Prod. Nat. 3, 1-55. doi: 10.1080/22311866.2013.782757

Aggarwal, B. B., Sundaram, C., Malani, N., and Ivhikawa, H. (2007). Curcumin: the Indian solid gold. Adv. Exp. Med. Biol. 595, 1-75. doi: 10.1007/978-0-38746401-5_1

Alice, A. F., Lopez, C. S., Lowe, C. A., Ledesma, M. A., and Crosa, J. H. (2006). Genetic and transcriptional analysis of the siderophore malleobactin biosyntesis and transport genes in the human pathogen Burkholderia pseudomallei. J. Bacteriol. 188, 1551-1556. doi: 10.1128/JB.188.4.1551-1566.2006

Ansel, H. C., Norred, W. P., and Roth, I. L. (1969). Antimicrobial activity od dimethyl sulfoxide against Escherichia coli, Pseudomonas aeruginosa, and Bacillus megaterium. J. Pharm. Sci. 58, 836-839. doi: 10.1002/jps.260 0580708

Antunes, L. C., Ferreira, R. B., Buckner, M. M., and Finlay, B. B. (2010). Quorum sensing in bacterial virulence. Microbiology 156, 2271-2282. doi: 10.1099/mic.0.038794-0 forcing the bacteria to re-focus on attaining fitness as opposed to killing of the host. Whilst curcumin has been documented as an anti-infective toward various pathogens, this is the first report that demonstrates the ability of curcumin to prolong the lifespan of the B. pseudomallei infected host. These preliminary findings provide invaluable insight into the interaction between curcumin and B. pseudomallei.

\section{Author Contributions}

SE and SN conceived and designed the experiments. SE performed the experiments. SE and SN analyzed the results and wrote the paper.

\section{Acknowledgments}

Natural extracts were provided by the Institute for Pharmaceuticals and Neutraceuticals Malaysia (IPharm). This project was funded by the Ministry of Science, Technology and Innovation, Malaysia (Grant No. 08-05-02-IFN-BPH002). SE was supported by the MyBrain15 Scholarship from the Ministry of Education Malaysia. We thank Dr. Man-Wah Tan (Genentech Inc, USA) for his advice and technical expertise.

\section{Supplementary Material}

The Supplementary Material for this article can be found online at: http://www.frontiersin.org/journal/10.3389/fmicb. 2015.00290/abstract

Supplementary Data 1 | Detailed information of all 42 natural products used in the anti-infective screening.

Supplementary Data 2 | List of differentially expressed B. pseudomallei genes in response to curcumin treatment.
Ashdown, L. R., and Koehler, J. M. (1990). Production of hemolysin and other extracellular enzymes by clinical isolates of Pseudomonas pseudomallei. J. Clin. Microbiol. 28, 2331-2334.

Baum, L., and Ng, A. (2004). Curcumin interaction with copper and iron suggested one possible mechanism of action in Alzheimer's disease animal models. J. Alzheimers Dis. 6, 367-377.

Beanan, M. J., and Strome, S. (1992). Characterization of a germ-line proliferation mutation in C. elegans. Development 116, 755-766.

Cegelski, L., Marshall, G. R., Eldridge, G. R., and Hultgren, S. J. (2008). The biology and future prospects of antivirulence therapies. Nat. Rev. Microbiol. 6, 17-27. doi: 10.1038/nrmicro1818

Cheng, A. C., and Currie, B. J. (2005). Melioidosis: epidemiology, pathophysiology, and management. Clin. Microbiol. Rev. 18, 383-416. doi: 10.1128/CMR.18.2.383-416.2005

Chieng, S., Carreto, L., and Nathan, S. (2012). Burkholderia pseudomallei transcriptional adaptation in macrophages. BMC Genomics 13:328. doi: 10.1186/14712164-13-328

Choh, L. C., Ong, G. H., Vellasamy, K. M., Kalaiselvam, K., Kang, W. T., Al-Maleki, A. R., et al. (2013). Burkholderia vaccines: are we moving forward? Front. Cell. Infect. Microbiol. 5:5. doi: 10.3389/fcimb.2013.00005

Clatworthy, A. E., Pierson, E., and Hung, D. T. (2007). Targeting virulence: a new paradigm for antimicrobial therapy. Nat. Chem. Biol. 3, 541-548. doi: $10.1038 /$ nchembio.2007.24 
Clinical and Laboratory Standards Institute (CLSI). (2006). Performance Standards for Antimicrobial Disk Susceptibility Test: Approved Standard, 9th Edn CLSI Document M2-A9. Wayne, PA: Clinical and Laboratory Standard Institute.

Cruz-Migoni, A., Hautberque, G. M., Artymiuk, P. J., Baker, P. J., Bokori-Brown, M., Chang, C. T., et al. (2011). A Burkholderia pseudomallei toxin inhibits helicase activity of translation factor eIF4A. Science 334, 821-824. doi: 10.1126/science. 1211915

de la Fuente-Nunez, C., Reffuveille, F., Fernandez, L., and Hancock, R. E. (2013). Bacterial biofilm development as an multicellular adaptation: antibiotic resistance and new therapeutic strategies. Curr. Opin. Microbiol. 16, 580-589. doi: 10.1016/j.mib.2013.06.013

Easton, D. M., Nijnik, A., Mayer, M. L., and Hancock, R. E. (2009). Potential of immunomodulatory host defense peptides as novel anti-infectives. Trends Biotechnol. 27, 582-590. doi: 10.1016/j.tibtech.2009.07.004

Eijkelkamp, B. A., Hassan, K. A., Paulsen, I. T., and Brown, M. H. (2011). Investigation of the human pathogen Acinetobactor baumannii under iron limiting conditions. BMC Genomics 12:126. doi: 10.1186/14712164-12-126

Gan, Y. H., Chua, K. L., Chua, H. H., Liu, B., Hii, C. S., Chong, H. L., et al. (2002). Characterization of Burkholderia pseudomallei infection and identification of novel virulence factors using a Caenorhabditis elegans host system. Mol. Microbiol. 44, 1185-1197. doi: 10.1046/j.13652958.2002.02957.x

Garsin, D. A., Sifri, C. D., Mylonakis, E., Qin, X., Singh, K. V., Murray, B. E., et al. (2001). A simple model host for identifying Gram-positive virulence factors. Proc. Natl. Acad. Sci. U.S.A. 98, 10892-10897. doi: 10.1073/pnas. 191378698

Gunes, H., Gulen, D., Mutlu, R., Gumus, A., Tas, T., and Eren Topkaya, A. (2013). Antibacterial effects of curcumin: an in vitro minimum inhibitory concentration study. Toxicol. Ind. Health. doi: 10.1177/0748233713498458. [Epub ahead of print].

Hamill, P., Brown, K., Jensses, H., and Hancock, R. E. (2008). Novel antiinfectives: is host defense the answer? Curr. Opin. Biotechnol. 19, 628-636. doi: 10.1016/j.copbio.2008.10.006

Hara, Y., Mohamed, R., and Nathan, S. (2009). Immunogenic Burkholderia pseudomallei outer membrane proteins as potential candidate vaccine targets. PLoS ONE 4:e6496. doi: 10.1371/journal.pone.0006496

Harland, D. N., Dassa, E., Titbal, R. W., Brown, K. A., and Atkins, H. S. (2007). ATP-binding cassette systems in Burkholderia pseudomallei and Burkholderia mallei. BMC Genomics 8:83. doi: 10.1186/1471-2164-8-83

Holden, M. T., Titbal, R. W., Peacock, S. J., Cerdeno-Tarraga, A. M., Atkins, T., Crossman, L. C., et al. (2004). Genomic plasticity of the causative agent of melioidosis, Burkholderia pseudomallei. Proc. Natl. Acad. Sci. U.S.A. 101, 14240-14245. doi: 10.1073/pnas.0403302101

Jiao, Y., Wilkinson, J. IV, Di, X., Wang, W., Hatcher, H., Knock, N. D., et al. (2009). Curcumin, a cancer chemopreventive and chemotherapeutic agent, is a biologically active iron chelator. Blood 113, 462-469. doi: 10.1182/blood-200805-155952

Jiao, Y., Wilkinson, J. IV, Pietsch, C. E., Buss, J. L., Wang, W., Planalp, R., et al. (2006). Iron chelation in the biological activity of curcumin. Free Radic. Biol. Med. 40, 1152-1160. doi: 10.1016/j.freeradbiomed.2005.11.003

Koh, S. F., Tay, S. T., and Puthucheary, S. D. (2013). Colonial morphology and biofilm forming ability of Burkholderia pseudomallei. Trop. Biomed. 30, 428-433.

Kong, C., Tan, M. W., and Nathan, S. (2014b). Orthosiphon stamineus protects Caenorhabditis elegans against Staphylococcus aureus infection through immunomodulation. Biol. Open 3, 644-655. doi: 10.1186/1472-6882-14-4

Kong, C., Yehye, W. A., Rahman, N. A., Tan, M. W., and Nathan, S. (2014a). Discovery of potential anti-infectives against Staphylococcus aureus using a Caenorhabditis elegans infection model. BMC Complement. Altern. Med. 14:4. doi: 10.1242/bio.20148334

Kouker, G., and Jaeger, K. E. (1987). Specific and sensitive plate assay for bacterial lipases. Appl. Environ. Microbiol. 53, 211-213.

Krewulak, K. D., and Vogel, H. J. (2008). Structural biology of bacterial iron uptake. Biochim. Biophys. Acta 1778, 1781-1804. doi: 10.1016/j.bbamem.2007.07.026

Kumarasamy, K. K., Toleman, M. A., Walsh, T. R., Bagaria, J., Butt, F., Balakrishnan, R., et al. (2010). Emergence of a new antibiotic resistance mechanism in India, Pakistan, and the UK: a molecular, biological and epidemiological study. Lancet Infect. Dis. 10, 597-602. doi: 10.1016/S14733099(10)70143-2

Lee, S. H., Chong, C. E., Lim, B. S., Chai, S. J., Sam, K. K., Mohamed, R., et al. (2007). Burkholderia pseudomallei animal and human isolates from Malaysia exhibit different phenotypic characteristics. Diagn. Microbiol. Dis. 58, 263-270. doi: 10.1016/j.diagmicrobio.2007.01.002

Lee, S. H., Ooi, S. K., Mahadi, N. M., Tan, M. W., and Nathan, S. (2011). Complete killing of Caenorhabditis elegans by Burkholderia pseudomallei is dependent on prolonged direct association with the viable pathogen. PLOS ONE 6:16707. doi: 10.1371/journal.pone.0016707

Lee, S. H., Wong, R. R., Chin, C. Y., Lim, T. Y., Eng, S. A., Kong, C., et al. (2013). Burkholderia pseudomallei suppresses Caenorhabditis elegans immunity by specific degradation of a GATA transcription factor. Proc. Natl. Acad. Sci. U.S.A. 110, 15067-15072. doi: 10.1073/pnas.1311725110

Liao, V. H., Yu, C. W., Chu, Y. J., Li, W. H., Hsieh, Y. C., and Wang, T. T. (2011). Curcumin-mediated lifespan extension in Caenorhabditis elegans. Mech. Ageing Dev. 132, 480-487. doi: 10.1016/j.mad.2011.07.008

Li, S., Yuan, W., Deng, G., Wang, P., and Aggarwal, B. B. (2011). Chemical composition and product quality control of turmeric (Curcuma longa L.). Pharm. Crops 2, 28-54. doi: 10.2174/2210290601102010028

Limmathurosatkul, D., Wongratanacheewin, S., Teerawattanasook, N., Wongsuvan, G., Chaisuknant, S., Chetchotisakd, P., et al. (2010). Increasing incidence of human melioidosis in northeast Thailand. Am. J. Trop. Med. Hyg. 82, 1113-1117. doi: 10.4269/ajtmh.2010.10-0038

Marathe, S. A., Ray, S., and Chakravortty, D. (2010). Curcumin increases the pathogenicity of Salmonella enterica serovar Typhimurium in murine model. PLOS ONE 5:e11511. doi: 10.1371/journal.pone.0011511

Moghadamtousi, S. Z., Kadir, H. A., Hassandarvish, P., Tajik, H., Abubakar, S., and Zandi, K. (2014). A review on antibacterial, antiviral, and antifungal activity of curcumin. Biomed. Res. Int. 2014:186864. doi: 10.1155/2014/186864

Moy, T. I., Ball, A. R., Anklesaria, Z., Casadei, G., Lewis, K., and Ausubel, F. M. (2006). Identification of novel antimicrobials using a live-animal model system. Proc. Natl. Acad. Sci. U.S.A. 103, 10414-10419. doi: 10.1073/pnas.0604055103

Neelakantan, P., Subbarao, C., Sharma, S., Subbarao, C. V., Garcia-Godoy, F., and Gutman, J. L. (2013). Effectiveness of curcumin against Enterococcus faecalis biofilm. Acta. Odontol. Scand. 71, 1453-1457. doi: 10.3109/00016357.2013.769627

Newman, D. J., and Cragg, G. M. (2012). Natural products as sources of new drugs over the 30 years from 1981 to 2010. J. Nat. Prod. 75, 311-335. doi: $10.1021 / \mathrm{np} 200906 \mathrm{~s}$

Nijnik, A. (2013). Immunomodulatory approaches for prevention and treatment of infectious diseases. Curr. Opin. Microbiol. 16, 590-595. doi: 10.1016/j.mib.2013.06.011

Ooi, S. K., Lim, T. Y., Lee, S. H., and Nathan, S. (2012). Burkholderia pseudomallei kills Caenorhabditis elegans through virulence mechanism distinct from intestinal lumen colonization. Virulence 3, 485-496. doi: 10.4161/viru.21808

O'Quinn, A. L., Wiegand, E. M., and Jeddeloh, J. A. (2001). Burkholderia pseudomallei kills the nematode Caenorhabditis elegans using an endotoxin-mediated paralysis. Cell Microbiol. 3, 381-393. doi: 10.1046/j.1462-5822.2001.00118.x

Packiavathy, I. A., Priya, S., Pandian, S. K., and Ravi, A. V. (2014). Inhibition of biofilm development of uropathogens by curcumin - an antiquorum sensing agent from Curcuma longa. Food Chem. 148, 453-460. doi: 10.1016/j.foodchem.2012.08.002

Papa, R., Artini, M., Cellini, A., Tilotta, M., Galano, E., Pucci, P., et al. (2013). A new anti-infective strategy to reduce the spreading of antibiotic resistance by the action on adhesion-mediated virulence factors in Staphylococcus aureus. Microb. Pathog. 63, 44-53. doi: 10.1016/j.micpath.2013.05.003

Patel, N., Conojero, L., De Reynal, M., Easton, A., Bancroft, G. J., and Titball, R. W. (2011). Development of vaccines against Burkholderia pseudomallei. Front. Microbiol. 2:198. doi: 10.3389/fmicb.2011.00198

Puah, S. M., Puthucheary, S. D., Wang, J. T., Pan, Y. J., and Chua, K. H. (2014). Molecular characterization of putative virulence determinants in Burkholderia pseudomallei. ScientificWorldJournal 2014:590803. doi: 10.1155/2014/590803

Puthucheary, S. D., and Sam, I. C. (2012). Why is the response rate slow in ceftazidime therapy for melioidosis? Expert Rev. Anti. Infect. Ther. 10, 5-7. doi: 10.1586/eri.11.158

Rodrigues, F., Sarkar-Tyson, M., Harding, S. V., Sim, S. H., Chua, H. H., Lin, C. H., et al. (2006). Global map of growth-regulated gene expression in Burkholderia 
pseudomallei, the causative agent of melioidosis. J. Bacteriol. 188, 8178-8188. doi: 10.1128/JB.01006-06

Rudrappa, T., and Bais, H. P. (2008). Curcumin, a known phenolic from Curcuma longa, attenuates the virulence of Pseudomonas aeruginosa PA01 in whole plant and animal pathogenicity models. J. Agric. Food Chem. 56, 1955-1962. doi: $10.1021 / \mathrm{jf072591j}$

Sarabhai, S., Sharma, P., and Capalash, N. (2013). Ellagic acid derivatives from Terminalia chebula Retz. downregulate the expression of quorum sensing genes to attenuate Pseudomonas aeruginosa PAO1 virulence. PLoS ONE 8:e53441. doi: 10.1371/journal.pone.0053441

Schwyn, B., and Neilands, J. B. (1987). Universal chemical assay for the detection and determination of siderophores. Anal. Biochem. 160, 47-56. doi: 10.1016/0003-2697(87)90612-9

Shapira, M., and Tan, M. W. (2008). Genetic analyis of Caenorhabditis elegans innate immunity. Methods Mol. Biol. 415, 429-442. doi: 10.1007/978-1-59745570-1_25

Sikora, E., Scapagini, G., and Barbagallo, M. (2010). Curcumin, inflammation, ageing and age-related diseases. Immun. Ageing 17:1. doi: 10.1186/1742-4933-7-1

Silva, B. S., and Dow, S. W. (2013). Development of Burkholderia mallei and pseudomallei vaccines. Front. Cell Infect. Microbiol. 3:10. doi: $10.3389 /$ fcimb. 2013.00010

Tabara, H., Hills, R. J., Mello, C. C., Priess, J. R., and Kohara, Y. (1999). pos-1 encodes a cytoplasmic zinc-finger protein essential for germline specification in Caenorhabditis elegans. Development 126, 1-11.

Tan, M. W., Mahajan-Miklos, S., and Ausubel, F. M. (1999). Killing of Caenorhabditis elegans by Pseudomonas aeruginosa used to model mammalian bacterial pathogenesis. Proc. Natl. Acad. Proc. Sci. U.S.A. 96, 715-720. doi: 10.1073/pnas.96.2.715

Tuanyok, A., Kim, H. S., Nierman, W. C., Yu, Y., Dunbar, J., Moore, R. A., et al. (2005). Genome-wide expression of iron regulation in Burkholderia pseudomallei and Burkholderia mallei using DNA microarray. FEMS Microbiol. Lett. 252, 327-335. doi: 10.1016/j.femsle.2005.09.043
Wiegand, I., Hilpert, K., and Hancock, R. E. W. (2008). Agar and broth dilution method to determine the minimal inhibitory concentration (MIC) of antimicrobial substances. Nat. Protoc. 3, 163-175. doi: 10.1038/ nprot.2007.521

Wiersinga, W. J., van der Poll, T., White, N. J., Day, N. P., and Peacock, S. J. (2006), Melioidosis: insights into the pathogenicity of Burkholderia pseudomallei. Nat. Rev. Microbiol. 4, 272-282. doi: 10.1038/nrmicrol385

Wuthiekanun, V., Amornchai, P., Saoprom, N., Chantratita, N., Chierakul, W., Koh, G. C. K. W., et al. (2011). Survey of antimicrobial resistance in clinical Burkholderia pseudomallei isolates over two decades in northeast Thailand. Antimicrob. Agents Chemother. 55, 5388-5391. doi: 10.1128/ AAC.05517-11

Yang, H., Kooi, C. D., and Sokol, P. A. (1993). Ability of Pseudomonas pseudomallei malleobactin to acquire transferrin-bound, lactoferrin-bound, and cell-derived iron. Infect. Immun. 61, 656-662.

Zilberberg, M. D., and Shorr, A. F. (2013). Prevalence of multidrug-resistant Pseudomonas aeruginosa and carbapenem-resistant Enterobacteriaceae among specimens from hospitalized patients with pneumonia and bloodstream infections in the United States from 2000 to 2009. J. Hosp. Med. 8, 559-563. doi: $10.1002 / \mathrm{jhm} .2080$

Conflict of Interest Statement: The authors declare that the research was conducted in the absence of any commercial or financial relationships that could be construed as a potential conflict of interest.

Copyright (c) 2015 Eng and Nathan. This is an open-access article distributed under the terms of the Creative Commons Attribution License (CC BY). The use, distribution or reproduction in other forums is permitted, provided the original author(s) or licensor are credited and that the original publication in this journal is cited, in accordance with accepted academic practice. No use, distribution or reproduction is permitted which does not comply with these terms. 